\title{
Platelet function in the postprandial period
}

\author{
Helmut Sinzinger ${ }^{1,2,3^{*}}$ and Robert Berent ${ }^{4}$
}

\begin{abstract}
Background: Postprandial hyperlipidemia and hyperglycemia have been related to cardiovascular events. Among different underlying mechanisms platelet activation seems to be responsible too. No comparable data between various tests in normo- vs. hyperlipidemics before and at different time intervals are available after a fat meal. We aimed to compare 9 of them within the same patients at several time points in postprandial hyperlipidemia.

Results: For some tests baseline values between the groups were significantly different ( $T X B_{2}$, platelet sensitivity, sedimentation and WU-test). However, hyperlipidemia revealed a variable influence on the tests examined. Some of the available tests apparently sensitive to show platelet activation reflect the increase in triglycerides (TG), such as the sedimentation index. ADP-induced platelet aggregatory activity in count adjusted washed isolated platelet samples during postprandial hyperlipidemia indicates mildly enhanced platelet activity, but does not seem to induce significant changes in aggregation. In patients with severe hypertriglyceridemia (> $400 \mathrm{mg} / \mathrm{dl}$ fasting) changes in platelet function are more pronounced due to delayed decay and may last up to 16 hours paralleling TG reaching the prevalue. The overwhelming majority of platelet function tests do not significantly respond to postprandial hyperlipidemia. The correlation between the tests applied is poor. For standardization purpose, platelet aggregation tests, aimed to examine proaggregatory capacity in atherosclerosis, should only be performed at the same time of the day after a fasting period $>6$ hours. The great variation in preanalytical work-up on comparison of various tests, large number of platelet tests available and their respective potential value are discussed.
\end{abstract}

Conclusions: At present, the suspicion that platelet function is significantly activated in the postprandial period cannot be supported by any of the tests used. The information provided is valuable to know for which test and group of patients a fasting period of which duration is recommendable.

Keywords: Postprandial hyperlipidemia, Platelet activity, Platelet aggregation, Platelet count, Atherosclerosis

\section{Introduction}

Long-term high intake of saturated fats is responsible for the morbidity and mortality in coronary heart disease. Postprandial (but not fasting) triglycerides [1] and small chylomicron remnants [2] were related to coronary heart disease and the progression of coronary atherosclerosis, respectively. Along this line, postprandial angina after a fat meal has been recognized for many centuries as a marker of severe coronary artery disease [3]. Moreover, a variety of studies are claiming an activation of platelets and plasmatic coagulation in the postprandial period [4,5]. Although the extent of postprandial (hyper-)lipidemia has been reported to

\footnotetext{
* Correspondence: helmut.sinzinger@chello.at

'Institute for Diagnosis and Treatment of Lipid Disorders and Atherosclerosis (ATHOS), Vienna, Austria

'Wilhelm Auerswald Atherosclerosis Research Group (ASF), Vienna, Austria

Full list of author information is available at the end of the article
}

imbalance hemostasis, the significance of postprandial lipid concentration, fatty acid metabolism and platelet function is still under debate. Repetitive activation of platelets could be responsible for initiation, development and progression of atherosclerosis and enhanced incidence of arterial thrombosis. While a variety of studies are available examining the response of various platelet function tests on differently induced postprandial stages, a comparative study running several tests in one particular patient after a standardized meal is not available.

A PubMed search performed on January $24^{\text {th }}, 2012$ using various key word combinations reveals a surprisingly small number of papers dealing with the issue of this contribution (Table 1).

\section{Patients and methods}

Blood for platelet function testing was always drawn during 7.30 a.m. and 9.00 a.m. in the morning after

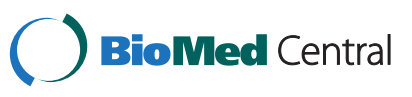

(c) 2012 Sinzinger and Berent; licensee BioMed Central Ltd. This is an Open Access article distributed under the terms of the Creative Commons Attribution License (http://creativecommons.org/licenses/by/2.0), which permits unrestricted use, distribution, and reproduction in any medium, provided the original work is properly cited. 
Table 1 PubMed literature survey

\begin{tabular}{lc}
\hline Key word & References found \\
\hline$P P$ & 16598 \\
$P P+P L$ & 125 \\
$P P+P L$ function & 121 \\
$P P+P L$ aggregation & 48 \\
$P P L+P L$ & 79 \\
$P P L+P L$ function & 79 \\
$P P L+P L$ aggregation & 33 \\
$P P G+P L$ & 38 \\
$P P G+P L$ function & 37 \\
$P P G+P L$ aggregation & 14 \\
$P P G+L+P L$ & 16 \\
$P P G+L+P L$ function & 16 \\
$P P G+L+P L$ aggregation & 6
\end{tabular}

PP . . . postprandial, PL ... platelet, L . . lipids, G . . glucose.

overnight fasting (more than 16 hours) from a nonoccluded cubital vein. Before blood withdrawal patients were allowed to rest for 30 minutes. For platelet function testing special care was taken in order to avoid ex-vivo and in-vitro activation. Platelet count was adjusted in all aggregation test samples to $250 \times 10^{3} / \mu$ l. Platelet function tests performed were the determination of platelet proteins ( $ß$-thromboglobulin, platelet factor 4) and plasma thromboxane $B_{2}$ by means of a radioimmunoassay, as well as platelet sensitivity to $\mathrm{PGI}_{2}$ (ADP-induced aggregation), sedimentation index, WU-test for reversible circulating platelet aggregates, retention, migration and in-vitro radiolabeling of platelets.

Postprandial testing was performed after a meal consisting of $80 \mathrm{~g}$ fat in 2 rolls. Familial hypercholesterolemia was defined as isolated total cholesterol $>250 \mathrm{mg} /$ $\mathrm{dl}$ without lipid lowering agents and severe familial hypertriglyceridemia (HTG) as fasting triglycerides (TG)-values above $400 \mathrm{mg} / \mathrm{dl}$ before treatment and after exclusion of secondary HTG. All participants were nonsmokers. None of the patients was taking any drug since $>2$ weeks before blood withdrawal.

\section{Statistical analysis}

Values are presented as $x \pm S D$, calculation for significance was done by Student's t-test. A $\mathrm{p}<0.01$ is considered as significant.

\section{Results}

The prevalues for thromboxane (TX) $\mathrm{B}_{2}$, the platelet sensitivity against prostaglandin (PG) $\mathrm{I}_{2}$, the WU-test and the sedimentation index (SI) show a difference between normolipemics vs. hypercholesterolemics (HC) and hyperlipidemics with metabolic syndrome (MS) (Table 2). All other parameters are not significantly different. Tests
Table 2 Prevalues of the platelet function parameters examined

\begin{tabular}{lcccl}
\hline Parameter & NL & HC & MS & Units \\
\hline count & $211 \pm 10$ & $216 \pm 13$ & $217 \pm 11$ & $\times 10^{3} / \mu l$ \\
BTG & $51.7 \pm 2.2$ & $55.6 \pm 2.3$ & $52.3 \pm 2.8$ & $\mathrm{pg} / \mathrm{ml}$ \\
PF4 & $16.6 \pm 2.4$ & $18.9 \pm 2.7$ & $18.6 \pm 2.5$ & $\mathrm{pg} / \mathrm{ml}$ \\
$\mathrm{TXB}_{2}$ & $7.4 \pm 1.3$ & $12.8 \pm 2.3^{*}$ & $10.7 \pm 1.9^{*}$ & $\mathrm{pg} / \mathrm{ml}$ \\
PS PG| & $0.96 \pm 0.09$ & $1.82 \pm 0.51^{*}$ & $1.65 \pm 0.22^{*}$ & $\mathrm{ng} / \mathrm{ml}$ \\
SI & $2.9 \pm 0.4$ & $4.1 \pm 0.6^{*}$ & $6.8 \pm 2.2^{*}$ & $\%$ \\
WU & $0.95 \pm 0.02$ & $0.86 \pm 0.04^{*}$ & $0.78 \pm 0.06^{*}$ & $\%$ \\
retention & $88.4 \pm 3.2$ & $87.1 \pm 3.7$ & $89.0 \pm 3.8$ & $\%$ \\
migration & $386 \pm 21$ & $397 \pm 26$ & $391 \pm 22$ & $\mathrm{~mm}$ \\
\hline
\end{tabular}

values in $\mathrm{x} \pm \mathrm{SD} ; \mathrm{n}=28$ each group $\left(14 \mathrm{~m} / 14 \mathrm{f}\right.$, aged $31-56$ years); $\left.{ }^{*}\right) \mathrm{p}<0.01$; NL indicates normolipemics; HC, hypercholesterolemics; MS, metabolic syndrome; PS, platelet sensitivity; count, platelet count; BTG, ß-thrombogloblin; PF4, platelet factor $4 ; \mathrm{TXB}_{2}$, thromboxane $\mathrm{B}_{2} ; \mathrm{PS} \mathrm{PGl}_{2}$, platelet sensitivity to prostaglandin $\mathrm{I}_{2} ; \mathrm{Sl}$, sedimentation index; WU, WU-test.

Only $\mathrm{TXB}_{2}, \mathrm{PS} \mathrm{PGI}$, SI and the WU-test reveal significant differences between $\mathrm{NL}$ vs. $\mathrm{HC}$ - and MS-patients, respectively. $\mathrm{TXB}_{2}$ and $\mathrm{PS} \mathrm{PGl}_{2}$ seem to be more closely related to cholesterol, SI and the WU-test to TG.

predominantly being based on the physical interaction between large lipoproteins and platelets, such as SI und WU-test, apparently are more pronounced in HTG while platelet sensitivity being a measure for the $\mathrm{PGI}_{2}$-surface receptors are more pronounced in hypercholesterolemia. The behaviour of the various tests after a fat meal is quite different. The trend towards an increase in peripheral platelet count is quite comparable in the 3 different groups of patients (Table 3 ) reaching only at 3 and 6 hours, respectively, statistical significance. A very severe increase can be noted for the SI being most pronounced in MS-patients. Interestingly, this response in MS-patients apparently correlating to the long-lasting increase in TG remains significant for $>12$ hours, while in normolipemics and $\mathrm{HC}$ the increase is much less pronounced and by far shorter lasting. The reason seems to be a correlation between SI and TG $(r=0.7413 ; p<0.001)$. All the other tests examined do not show any significant change after the fat load (Table 3 ).

Measuring ADP-response of platelets in platelet rich plasma revealed a decreased response in the tangent of the response curve (data not shown) as well as the maximal amplitude (Table 4). In contrast, testing isolated washed platelets there is a trend towards an increase in aggregation response which is significant for $\mathrm{HC}$ after 3 hours and for MS up to 6 hours. Also the extent of the change is most pronounced in MS patients. In (normal weight) patients with severe familial HTG deviation of aggregation response to ADP is more pronounced and longer lasting as compared to HC- and even MS-patients (Table 5).

\section{Discussion}

\section{Postprandial period}

Platelet function testing in dyslipoproteinemias suggested that lysolecithin and phosphatidylinositol may be involved 
Table 3 Influence of a fat meal on platelet function parameters

\begin{tabular}{|c|c|c|c|c|}
\hline & 3 hours & 6 hours & 12 hours & group \\
\hline \multirow[t]{3}{*}{ count } & $5.2(3.3)$ & $7.5(2.2)^{*}$ & $3.1(1.4)$ & $\mathrm{NL}$ \\
\hline & $4.9(2.6)$ & $8.3(2.5)^{*}$ & 4.2. (1.5) & $\mathrm{HC}$ \\
\hline & $5.0(2.4)$ & $7.7(1.8)^{*}$ & 2.9 (1.3) & MS \\
\hline \multirow[t]{3}{*}{ BTG } & $1.5(5.3)$ & $2.1(5.0)$ & $1.0(3.8)$ & $\mathrm{NL}$ \\
\hline & $2.1(6.3)$ & $3.0(7.1)$ & $2.8( \pm 5.4)$ & $\mathrm{HC}$ \\
\hline & $0.7(8.4)$ & $1.3(10.6)$ & $-0.3(6.4)$ & MS \\
\hline \multirow[t]{3}{*}{ PF4 } & $0.7(5.3)$ & $2.3(2.8)$ & $-1.4(5.2)$ & $\mathrm{NL}$ \\
\hline & $1.3(4.8)$ & $2.0(4.2)$ & $0.8(6.3)$ & $\mathrm{HC}$ \\
\hline & 1.1. (3.6) & $1.2(5.7)$ & $-1.1(5.4)$ & MS \\
\hline \multirow[t]{3}{*}{$\mathrm{TXB}_{2}$} & $4.2(12.2)$ & $0.3(6.3)$ & $-1.3(3.8)$ & $\mathrm{NL}$ \\
\hline & $-0.6(8.5)$ & $1.4(5.4)$ & $1.7(6.5)$ & $\mathrm{HC}$ \\
\hline & $2.0(9.1)$ & $1.3(7.5)$ & $-0.6(7.1)$ & MS \\
\hline \multirow[t]{3}{*}{$\left.P S P^{\prime}\right|_{2}$} & $-1.3(4.4)$ & $-0.5(3.1)$ & $-0.2(3.6)$ & $\mathrm{NL}$ \\
\hline & $1.0(2.7)$ & $0.6(2.3)$ & $0.7(2.7)$ & $\mathrm{HC}$ \\
\hline & $-0.8(2.5)$ & $0.9(3.1)$ & $1.3(1.9)$ & MS \\
\hline \multirow[t]{3}{*}{ SI } & $28.7(30.3)$ & $2.1(20.2)$ & $3.6(10.6)$ & $\mathrm{NL}$ \\
\hline & $21.4(17.9)$ & $0.6(14.3)$ & $2.0(7.5)$ & $\mathrm{HC}$ \\
\hline & $84.6(25.8)^{*}$ & $86.3(21.6)^{*}$ & $26.8(13.9)^{*}$ & MS \\
\hline \multirow[t]{3}{*}{ WU } & $3.4(4.6)$ & $2.7(2.4)$ & $0.7(3.4)$ & $\mathrm{NL}$ \\
\hline & $2.7(3.3)$ & $1.0(3.1)$ & $1.6(2.6)$ & $\mathrm{HC}$ \\
\hline & $3.3(3.3)$ & $2.2(3.7)$ & $2.5(4.1)$ & MS \\
\hline \multirow[t]{3}{*}{ retention } & - $3.1(6.3)$ & $4.7(7.4)$ & $2.2(3.9)$ & $\mathrm{NL}$ \\
\hline & $2.4(5.9)$ & $2.5(5.8)$ & $0.4(6.2)$ & $\mathrm{HC}$ \\
\hline & $4.7(6.1)$ & $6.8(6.0)$ & $2.1(4.5)$ & MS \\
\hline \multirow[t]{3}{*}{ migration } & $1.3(3.2)$ & $2.4(3.4)$ & $2.0(3.20$ & $\mathrm{NL}$ \\
\hline & $2.8(2.7)$ & $2.4(4.0)$ & $1.7(2.0)$ & $\mathrm{HC}$ \\
\hline & $2.2(3.8)$ & $2.0(3.9)$ & $1.1(1.8)$ & MS \\
\hline
\end{tabular}

$\mathrm{n}=12$ each $(6 \mathrm{~m} / 6 \mathrm{f}$, age $30-48$ years); values in \% vs. prevalue (SD); *) $\mathrm{p}<0.01$; for abbreviations see Table 2 .

A fat meal increases only peripheral platelet count (maximum at 6 hours) in all groups, SI only in MS-patients for up to 16 hours.

Table 4 ADP-response of washed platelets (WP) vs. in platelet-rich plasma (PRP)

\begin{tabular}{ccccc}
\hline & $\mathbf{3}$ hours & $\mathbf{6}$ hours & $\mathbf{1 2}$ hours & group \\
\hline WP & $3.7(7.1)$ & $2.2(5.4)$ & $0.6(4.1)$ & $\mathrm{NL}$ \\
& $4.3(3.3)^{*}$ & $1.4(3.8)$ & $-0.2(3.3)$ & $\mathrm{HC}$ \\
& $15.3(6.2)^{*}$ & $12.7(6.0)^{*}$ & $4.7(2.9)$ & $\mathrm{MS}$ \\
PRP & $-4.2(5.3)$ & $-2.6(2.4)$ & $1.0(1.6)$ & $\mathrm{NL}$ \\
& $-4.0(3.9)$ & $-1.1(2.3)$ & $-0.4(0.9)$ & $\mathrm{HC}$ \\
& $-13.7(5.9)^{*}$ & $-11.6(3.1)^{*}$ & $-3.3(1.5)$ & $\mathrm{MS}$ \\
\hline
\end{tabular}

$\mathrm{n}=20$ each ( $12 \mathrm{~m} / 8 \mathrm{f}$, age $30-48$ years); values in \% change (SD) vs. prevalue; WP indicates washed platelets; PRP, platelet-rich plasma; for further abbreviations see Table 2.

Aggregation response is mainly influenced during the initial 3 hours after a meal in MS-patients. In NC and HC the alterations are small and short lasting. In WP there is an in part significant activation, while in PRP turbidity causes a decrease to a comparable extent.
Table 5 Platelet aggregation in washed platelets vs. platelet-rich plasma in severe familial hypertriglyceridemia

\begin{tabular}{|c|c|c|c|c|c|c|}
\hline & 1 hour & 3 hours & 6 hours & 12 hours & 16 hours & \\
\hline \multirow[t]{2}{*}{ A.S. 41,0} & -10.6 & -15.7 & -17.3 & -10.8 & -1.0 & PRP \\
\hline & 13.4 & 18.9 & 20.3 & 11.4 & 2.3 & WP \\
\hline \multirow[t]{2}{*}{ D.R. 37, q } & -9.2 & -13.7 & -15.4 & -8.6 & -0.3 & PRP \\
\hline & 12.0 & 16.2 & 17.3 & 10.3 & 0.4 & WP \\
\hline \multirow[t]{2}{*}{ J.O. 29, ठ } & -7.6 & -12.2 & -12.1 & -7.6 & -0.9 & PRP \\
\hline & 10.1 & 13.8 & 14.7 & 9.9 & 2.0 & WP \\
\hline \multirow[t]{2}{*}{ H.M. 54, ठ } & -11.3 & -14.7 & -18.6 & -11.7 & -3.3 & PRP \\
\hline & 13.0 & 17.2 & 21.1 & 13.0 & 4.1 & WP \\
\hline \multirow[t]{2}{*}{ D.W. 44, 万人 } & -8.6 & -9.3 & -12.9 & -5.4 & -1.6 & PRP \\
\hline & 11.0 & 12.6 & 15.2 & 8.4 & -0.3 & WP \\
\hline
\end{tabular}

values in \% changes vs. prevalue; PRP indicates platelet-rich plasma; WP, washed platelets.

In severe HTG platelet function change induced by ADP is particularly long lasting up to 16 hours. Calculating the group statistics reveals that after 16 hours differences are no longer significant.

in modulating platelet response to aggregating agents [6]. Early reports showed that acute postprandial HTG causes moderate activation as examined in isolated platelets [7-9]. The platelet proteins $ß$-thromboglobulin (ßTG) and platelet factor 4 (PF4) were reported to be unaffected by a fat meal [10], while, in contrast, at the same time P-selectin expression was increased. Platelet microparticles exhibiting proatherogenic and procoagulant properties have been found to be increased in postprandial HTG showing a significant correlation to the actual TG level measured [11]. Although fat meals have shown acute effects on platelet function, apparently they are not mediated via the fatty acid composition of the acute meal [12]. Using isolated washed platelets derived from postprandial blood samples, Aviram's group [13-15] in a broad set of experiments found that the intake of fat meals induces an acute disturbance in platelet aggregation. The changes are more pronounced in hyperlipemic patients and after a saturated fat meal. Nordoy et al. confirmed that, as an acute intake of saturated and polyunsaturated fatty acids increases platelet sensitivity to thrombin and collagen $[8,9]$.

The methodological aspect is highlighted by a report $[16,17]$ that the consumption of $100 \mathrm{~g}$ fat after a 12 hours fasting period causes a significant decrease (!!) in platelet aggregability upon both, ADP and collagen. The authors did not discover a correlation between the inhibition of platelet aggregation and the increase in TG during postprandial hyperlipidemia. This reduction in maximum platelet aggregation response during the postprandial stage $(\mathrm{p}<0.001)$ was also described by Ahuja et al. [18]. At the same time there was no change in PG, including $\mathrm{TXB}_{2}$. However, in agreement with Aviram's and Nordoy's findings $[8,9,13,14]$, using washed human 
platelets we were able to show that platelet activity is not significantly affected and the changes described are simply due to the turbidity of the plasma [19,20], a phenomenon usually seen when TG exceeding $400 \mathrm{mg} / \mathrm{dl}$.

TX was not influenced, irrespective of whether the fat meal was taken together or without alcohol [21]. The interpretation of the data is further complicated by the fact that postprandial hyperinsulinemia stimulates platelet aggregation [22] which might particularly interfere in MS-patients, a large ever growing part of the population. On the contrary, in hyperinsulinemia a reduced platelet aggregation (ADP, collagen, epinephrine) was reported when euglycemia was maintained by clamping [23]. Westerbacka et al. described that normal in-vivo insulin action inhibits platelet interaction with collagen and aggregation with several agonists [24]. After a fat meal Wiens et al. found in healthy volunteers no change in platelet function tested by the platelet function analyzer (PFA-100) and circulating platelet aggregates, the socalled WU-test [25]. They note a postprandial increase in platelet count at 6 hours up to $8 \%$ from baseline which is in agreement with our findings $(\mathrm{x}=7.5-8.3 \%)$. Using the PFA-100, Karepov reported that HTG significantly influences platelet response to acetylsalicylic acid (ASA) [26], a finding which has not been confirmed by any other test. Different platelet preparation with respect to fasting prior blood withdrawal for platelet function testing is responsible for conflicting results.

Assuming that tea is frequently consumed with a meal, testing postprandial platelet aggregation on ADP was not different [27] in presence vs. absence of tea consumption. The evening meal did not have an influence on shear-induced platelet aggregation and urinary TX excretion either [21]. Delgado-Lista et al. showed that long-term ingestion of saturated versus non-saturated and omega-3 fatty acids resulted in a comparable postprandial response while basal levels were different [28]. In an in-vitro approach, virgin olive oil was shown to reduce $\mathrm{TXB}_{2}$ [29]. In 31 healthy subjects acute alimentary lipemia resulted in a decreased expression of CD40L on platelets and a reduced plasma level, suggesting an enhanced turnover [30].

GMP-140, an $\alpha$-granule membrane protein, was shown to be positively $(\mathrm{p}<0.01)$ correlated to total- $(\mathrm{r}=0.647)$ as well as LDL-cholesterol $(r=0.833)$, but not to TG [31]. In contrast, $\beta-T G$ and PF4 also derived from $\alpha$ granules apparently are not significantly elevated in $\mathrm{HC}$. Flow cytometry with monoclonal antibodies showed that platelet P-selectin expression was significantly higher 2 $1 / 2$ hours after a $40 \%$ fat meal consumption as compared to fasting values which were achieved again after 6 hours. In contrast, platelet monocyte aggregation increased up to 6 hours [5]. In these healthy normal-weight people TG increased by about $50 \%[18,32]$.

\section{Metabolic syndrome (MS)}

An ever increasing number of people are suffering from overweight and adiposity-induced MS with elevated TG and low HDL-cholesterol. MS patients have been characterized by a proinflammatory stage and a positive correlation to platelet activity markers [33]. HTG itself has been linked with platelet activation. Very low-density lipoproteins (VLDL) and remnant lipoproteins are associated with MS. VLDL and remnant lipoproteins elevated in patients with MS have the capacity to activate platelets [34]. The increasing number of people with MS may reveal different TG kinetics, in some of them normalization after a single meal in some of them may last up to 16 hours [35]. In type II diabetics the enhanced postprandial platelet reactivity was not influenced by glibenclamide or repaglinide [36] suggesting a lipid mediated action.

\section{Other factors to be considered Role of modification of lipoproteins}

In hypertriglyceridemic subjects the rate of oxidative modification of lipoproteins (VLDL, LDL, HDL, Lp(a)) is greatly increased. Waist circumference has been associated with an augmented oxidation injury as evidenced by isoprostane (8-epi-PGF $2 \alpha$ ) measurement. MS-patients may also show other types of modification, for instance glycation, glycoxidation, or malonylation. Platelet maximal aggregation was reported to be significantly $(\mathrm{p}<0.05-0.01)$ increased [37] after oxidative modification of the respective lipoprotein. In-vitro experiments have demonstrated that advanced glycation end products may enhance platelet activity assessed by a variety of tests several-fold [38]. Platelet NO-production was significantly related with body-mass index, waist circumference in HTG [39] and glycation of LDL [40]. However, platelet NO-sensitivity postprandially has been shown to be unchanged [35]. A reduced paraoxonase activity correlating with low HDL-levels in HTG indicates an impairment in enzymatic antioxidant activity [41].

\section{Low HDL in diabetes mellitus (DM)}

A major clinical problem with type $2 \mathrm{DM}$ is the enhanced platelet reactivity resulting in a prothrombotic state. As a consequence, diabetic platelets have been claimed to be less sensitive to antithrombotic drugs [42]. However, antithrombotic treatment has little impact on the stability of vulnerable plaques and does not target the phenomenon of platelet hyperreactivity. Recently, Calkin et al. reported that administration of reconstituted HDL caused a reduction of platelet aggregation response in DM subjects by promoting cholesterol efflux from platelets with an increased cholesterol content [43]. These findings demonstrate that reconstituted HDL is highly effective at reversing the excessive accumulation of 
cholesterol in platelet membranes in patients with low HDL as in diabetics. Furthermore, attention should be focused on the functionality of HDL. HDL may act as an antioxidant for LDL while becoming oxidized itself loosing significant parts of its atheroprotective benefits.

\section{Hypertriglyceridemia (HTG)}

HTG has been associated with cardiovascular disease since the early 70ies [44]. HTG is known to enhance platelet activation [45]. One responsible mechanism is the pathway via the apoE content of VLDL particles [46] and their interaction with the platelet LDL receptors. Moreover, successful treatment of HTG with bezafibrate decreases platelet GP53 expression, but not P-selectin and fibrinogen binding in a double-blind placebo-controlled study [45].

Elevated levels of non-fasting/postprandial TG directly correlate with elevated remnant cholesterol VLDL and remnant lipoproteins have the capacity to activate platelets and are closely associated with atherosclerosis [47].

\section{Methodological standardization}

At present there is still no widely agreed definition of postprandial lipemia [48]. There is also conflicting information on blood collection and platelet processing regarding fasting and feeding states [18]. Our data clearly indicate that for platelet function testing standardization of blood withdrawal is needed. Fasting TG levels are necessary to be standardized, but nonfasting levels much better reflect the cardiovascular risk much better $[44,49]$. Therefore, a fasting sample for platelet function studies should be mandatory [18] unless the objective is to determine acute effects of drugs and/or food. No studies as to the type of hyperlipidemia (vs. normolipemia), time-dependency and the TG kinetics are available.

Aznar et al. confirmed this inhibitory effect of TG on platelet activation [50] while in presence of chylomicrons no modification in platelet aggregation was revealed, which is in accordance with our findings. A circadian rhythm of platelet activity has also been claimed to be responsible for the increased incidence of cardiovascular events early in the day [51-53]. Permanent hyperlipidemia causes a different fatty acid content [54], membrane composition $[6,55]$ and membrane fluidity of platelets. This results in an altered functional and labeling behaviour [56]. In contrast, platelets taken during postprandial hyperlipidemia even in severe HTG do not exhibit a different labeling behaviour (Table 6). On the other hand, the dietary fatty ingestion may induce an altered sensitivity of platelets to aggregation inducing agents [57]. A long-term mono-unsaturated fatty acid rich diet as a matter of fact by influencing platelet membrane fatty acid composition [58] was shown to reduce
Table 6 Influence of fasting on radiolabelling behaviour of platelets with ${ }^{111}$ In-oxine

\begin{tabular}{lccccl}
\hline & NL & HC & MS & HTG & \\
\hline LE & $90.6 \pm 2.7$ & $46.2 \pm 3.8^{*}$ & $86.9 \pm 2.9$ & $88.8 \pm 2.7$ & fasting \\
& $89.7 \pm 2.5$ & $46.8 \pm 4.3^{*}$ & $87.5 \pm 2.2$ & $88.4 \pm 1.9$ & non-fasting \\
REC & $68.2 \pm 3.0$ & $22.7 \pm 5.2^{*}$ & $63.7 \pm 5.8$ & $67.5 \pm 4.0$ & fasting
\end{tabular}

values in $\%($ mean $\pm S D) ; n=12$ each subgroup $(6 \mathrm{~m} / 6 \mathrm{f}) ; *) p<0.01$ (vs. NL); LE indicates labelling efficiency; REC, recovery; for further abbreviations see Table 2 . Postprandial hyperlipidemia does not affect LE or REC in any of the patient groups.

platelet aggregation induced by ADP and arachidonic acid in healthy young people.

Platelet lipoprotein binding has been claimed to be related to platelet reactivity. Patients with clinically manifested atherosclerosis, hypercholesterolemia and DM exhibit a significantly decreased high-affinity LDL- and HDL-binding on platelets $[59,60]$ being associated with an increased platelet activity as demonstrated for $\mathrm{TXB}_{2}$, platelet proteins and ADP-induced platelet aggregation. This inverse relation has been found to be reversed with lipid lowering (statins, etofibrate, gemfibrozil, cholestyramine) treatment [61]. While the chronic effect of increased lipids and lipoproteins on platelet lipoprotein binding sites is well investigated, it is unknown whether there are acute changes during postprandial hyperlipidemia reflected at the platelet LDL- and/or HDL-receptor level.

Postprandial hyperglycemia in early type II diabetics was associated with an increased platelet activation as judged by the urinary excretion of the elevated 11-dehydro- $\mathrm{TXB}_{2}$-compound [62] and an activation of protein kinase $C\left(\alpha, \beta_{1}, \beta_{2}\right)$ in platelets, a potential candidate for mediating increased cardiovascular risk [63].

Only few data are available for most of the tests. The SI [64] defined as the percentage of platelets in platelet rich plasma (PRP) after centrifugation at $1600 \mathrm{~g}$ vs. PRP is the only one parameter which is found significantly increased after a fat meal known and correlates well with TG [65] apparently reflecting physical interaction of platelets with large lipoprotein particles.

The prevalues of various platelet function parameters reveal that the platelet sensitivity to $\mathrm{PGI}_{2}$ is the most abnormal parameter in HCNMS vs. NL. On the other hand, the SIN metabolic syndrome beside the Wu-test shows the most pronounced changes. A fat meal in all the 3 groups tested shows an increase in peripheral platelet count, while the sedimentation index is only significantly altered in MS-patients. Remarkably (Table 4), the platelet function testing reveals an opposite behaviour if done in washed cells vs. PRP, the elevated triglyceride rich lipoproteins being responsible for the change in the transmission. The individual follow-up monitoring up to 16 hours shows that there is a discrepancy in the results of platelet aggregation performed in washed 
platelets vs. those in PRP, which at 16 hours fasting almost disappears.

Interestingly, radiolabeling behaviour of platelet only significantly affected in patients with hypercholesterolemia, apparently due to the different membrane composition, fasting had no significant effect on labeling efficiency as on recovery.

As a matter of fact, all the data discussed in this paper were derived from non-smokers. While it is well known that the baseline values for most of the tests are differing between cigarette smokers and non-smokers, a comparative evaluation of these 2 groups on either a carbohydrate rich or a fat meal has not been performed. Other components such as obesity and hypertension may alter baseline platelet function. However, only in MS-patients the postprandial response seems to be influenced. Moreover, fat load varies considerably, only one recent review by an expert panel recommended a preferable amount of fat of about $75 \mathrm{~g}$ [66].

This is the first comparative study using a broader spectrum of tests in one and the same patient. Platelet function tests show a great variability and differ between the groups examined. As no single standardized and validated platelet function test is available, no clinically valid conclusions can be drawn.

\section{Abbreviations}

ADP: Adenosin diphosphate; DM: Diabetes mellitus;

HC: Hypercholesterolemics; HDL: High-density lipoprotein;

HTG: Hypertriglyceridemia; MS: Metabolic syndrome; PF4: Platelet factor 4; PFA: Platelet function analyzer; PRP: Platelet rich plasma; PFA-100: Platelet function analyzer; PF: Platelet sensitivity; PG: Prostaglandins; TG: Triglycerides; BTG: B-thromboglobulin; TX: Thromboxane; VLDL: Very low-density lipoproteins.

\section{Competing interests}

The authors declare that they have no competing interests.

\section{Authors' contributions}

$\mathrm{HS}$ and RB reviewed the literature, drafted the manuscript, and revised the manuscript. All authors read and approved the final manuscript.

\section{Author details}

'Institute for Diagnosis and Treatment of Lipid Disorders and Atherosclerosis (ATHOS), Vienna, Austria. ${ }^{2}$ Wilhelm Auerswald Atherosclerosis Research Group (ASF), Vienna, Austria. ${ }^{3}$ Department of Nuclear Medicine, Medical University of Vienna, Vienna, Austria. ${ }^{4}$ Center for Cardiovascular Rehabilitation, Rehabilitationszentrum Austria, Bad Schallerbach, Austria.

Received: 13 February 2012 Accepted: 27 August 2012

Published: 3 September 2012

\section{References}

1. Patsch JR, Miesenböck G, Hopferwieser T, Mühlberger V, Knapp E, Dunn JK, Gotto AM Jr, Patsch W: Relation of triglyceride metabolism and coronary artery disease. Studies in the postprandial state. Arterioscler Thromb 1992 12:1336-1345.

2. Karpe F, Steiner G, Uffelman K, Olivecrona T, Hamsten A: Postprandial lipoproteins and progression of coronary atherosclerosis. Atherosclerosis 1994, 106:83-97.

3. Berlinerblau R, Shani J: Postprandial angina pectoris: clinical and angiographic correlations. J Am Coll Cardiol 1994, 23:627-629.

4. Duttaroy AK: Postprandial activation of hemostatic factors: Role of dietary fatty acids. Prostagl Leukot Essent Fatty Acids 2005, 72:381-391.
5. Hyson DA, Paglieroni TG, Wun T, Rutledge JC: Postprandial lipemia is associated with platelet and monocyte activation and increased monocyte cytokine expression in normolipemic men. Clin Appl Thromb Hemost 2002, 8:147-155.

6. Shastri KM, Carvalho ACA, Lees RS: Platelet function and platelet lipid composition in the dyslipoproteinemias. J Lipid Res 1980, 21:467.

7. Belch JJF, Sanibaldi AR, McLaughlin K, Forbes CD: Platelet changes after a saturated fat meal and their preventions by Dazmegrel, a thromboxane synthetase inhibitor. Lipids 1987, 22:159-162.

8. Nordoy A, Strom E, Gjesdal K: The effect of alimentary hyperlipaemia and primary hypertriglyceridaemia on platelets in man. Scand J Haematol 1974, 12:329-340.

9. Nordoy A, Lagarde M, Renaud S: Platelets during alimentary hyperlipaemia induced by cream and cod liver oil. Eur J Clin Invest 1984, 14:339-345.

10. Bröijersén A, Karpe F, Hamsten A, Goodall AH, Hjemdahl P: Alimentary lipemia enhances the membrane expression of platelet P-selectin without affecting other markers of platelet activation. Atherosclerosis 1998, 137:107-113.

11. Michelsen AE, Noto AT, Brodin E, Mathiesen EB, Brosstad F, Hansen JB: Elevated levels of platelet microparticles in carotid atherosclerosis and during the postprandial state. Thromb Res 2009, 123:881-886.

12. Freese R, Mutanen M: Postprandial changes in platelet function and coagulation factors after high-fat meals with different fatty acid compositions. Eur J Clin Nutr 1995, 49:658-664.

13. Aviram M, Fuhrman B, Brook JG: Postprandial plasma lipoproteins in normal and hypertriglyceridaemic subjects and there in vitro effect on platelet activity: differences between saturated and polyunsaturated fats. Scand J Clin Lab Invest 1986, 46:571-579.

14. Aviram M, Rosenblat M, Potesman M, Dankner G, Brook JG: Plasma lipoprotein and platelet function after heparin injection: studies in normal fasted and postprandial and in type $\mathrm{V}$ hyperlipoproteinemic subjects. Biochem Med Metab Biol 1986, 35:279-292.

15. Fuhrman B, Brook JG, Aviram M: Increased platelet aggregation during alimentary hyperlipemia in normal and hypertriglyceridemic subjects. Ann Nutr Metab 1986, 30:250-260.

16. Nimpf J, Malle E, Leopold B, Wurm H, Kostner GM: Postprandial hyperlipemia inhibits platelet aggregation without affecting prostanoid metabolism. Prostagl Leukotr Essent Fatty Acids 1989, 37:7-13.

17. Malle E, Nimpf J, Leis HJ, Wurm H, Kostner GM: Postprandial hyperlipemia and platelet eicosanoid metabolism. Klin Wochenschr 1990, 68:116.

18. Ahuja KD, Adams MJ, Robertson IK, Ball MJ: Acute effect of a high-carbohydrate low-fat meal on platelet aggregation. Platelets 2009, 20:606-609.

19. Bisovsky S, Richter H, Fitscha P, O'Grady J, Sinzinger H: Postprandial hyperlipemia does not inhibit platelet aggregation. Prostagl Leukotr Essent Fatty Acids 1992, 47:331-332.

20. Sinzinger $\mathrm{H}$, Pirich C, Fitscha $P, O^{\prime}$ Grady J: Enhanced in-vitro platelet aggregability during postprandial hyperlipidaemia. Lancet 1993, 341:48.

21. Numminen $H$, Kobayashi M, Uchiyama S, Iwata M, Ikeda Y, Riutta A, Syrjälä M, Kekomäki R, Hillbom M: Effects of alcohol and the evening meal on shear-induced platelet aggregation and urinary excretion of prostanoids. Alcohol Alcohol 2000, 35:594-600.

22. Randriamboavonjy $\bigvee$, Fleming I: Insulin, insulin resistance and platelet signaling in diabetes. Diabetes Care 2009, 32:528-530.

23. Hiramatsu K, Nozaki H, Arimori S: Reduction of platelet aggregation induced by euglycaemic insulin clamp. Diabetologia 1987, 30:310-313.

24. Westerbacka J, Yki-Jarvinen H, Turpeinen A, Rissanen A, Vehkavaara S, Syrjala M, Lassila R: Inhibition of platelet-collagen interaction: An in-vivo action of insulin abolished by insulin resistance in obesity. Thromb Vasc Biol 2002, 22:167-172.

25. Wiens L, Lutze G, Luley C, Westphal S: Platelet count and platelet activation: impact of a fat meal and day time. Platelets 2007, 18:171-173.

26. Karepov V, Tolpina G, Kuliczkowski W, Serebruany V: Plasma triglycerides as predictors of platelet responsiveness to aspirin in patients after first ischemic stroke. Cerebrovasc Dis 2008, 26:272-276.

27. Hodgson JM, Puddey IB, Burke V, Beilin LJ, Mori TA, Chan SY: Acute effects of ingestion of black tea on postprandial platelet aggregation in human subjects. Brit J Nutr 2002, 87:141-145.

28. Delgado-Lista J, Lopez-Miranda J, Cortés B, Perez-Martinez P, Lozano A, Gomez-Luna R, Gomez P, Gomez MJ, Criado J, Fuentes F, Perez-Jimenez F: 
Chronic dietary fat intake modifies the postprandial response of hemostatic markers to a single fatty test meal. Am J Clin Nutr 2008, 87:317-322.

29. Perona JS, Martinez-González J, Sanchez-Dominguez JM, Badimon L, Ruiz-Gutierrez V: The unsaponifiable fraction of virgin olive oil in chylomicrons from men improves the balance between vasoprotective and prothrombotic factors released by endothelial cells. J Nutr 2004 134:3284-3289.

30. Kälsch T, Elmas E, Nguyen XD, Kralev S, Leweling H, Klüter H, Dempfle CE, Borggrefe M: Effects of alimentary lipemia and inflammation on platelet CD40-ligand. Thromb Res 2007, 120:703-708.

31. Shen T, Liu BW, Liu Y, Bai H, Zhang ZH: Effects of hypertriglyceridemia on platelet activities in endogenous hypertriglyceridemic patients. Sichuan Da Xue Xue Bao Yi Xue Ban 2004, 35:15-17.

32. Undar L, Akkoc N, Alakavuklar MN, Cehreli C, Undar L: Flow cytometric analysis of circadian changes in platelet activation using anit-GMP-140 monoclonal antibody. Chronobiol Int 1999, 16:335-342.

33. Unek IT, Bayraktar F, Solmaz D, Ellidokuz H, Yuksel F, Sisman AR, Yesil S: Enhanced levels of soluble CD40 ligand and C-reactive protein in a total of 312 patients with metabolic syndrome. Metabolism 2010, 59:305-313.

34. Olufadi R, Byrne CD: Effects of VLDL and remnant particles on platelets. Pathophysiol Haemost Thromb 2006, 35:281-291.

35. Anderson RA, Ellis GR, Evans LM, Morris K, Chirkov YY, Horowitz JD, Jackson SK, Rees A, Lewis MJ, Frenneaux MP: Platelet nitrate responsiveness in fasting and postprandial type 2 diabetes. Diab Vasc Dis Res 2005, 2:88-93.

36. Yngen M, Ostenson CG, Hjemdahl P, Wallén NH: Meal-induced platelet activation in type 2 diabetes mellitus: effects of treatment with repaglinide and glibenclamide. Diabet Med 2006, 23:134-140.

37. Bai H, Liu BW, Deng Z, Shen T, Fang DZ, Zhao YH, Liu Y: Plasma very-lowdensity lipoprotein, low-density lipoprotein, and high-density lipoprotein oxidative modification induces procoagulant profiles in endogenous hypertriglyceridemia. Free Radic Biol Med 2006, 40:1796-1803.

38. Gawlowski T, Stratmann B, Ruetter R, Buenting CE, Menart B, Weiss J, Vlassara H, Koschinsky T, Tschoepe D: Advanced glycation end products strongly activate platelets. Eur J Nutr 2009, 48:475-481.

39. Vignini A, Nanetti L, Moroni C, Testa R, Sirolla C, Marra M, Cenerelli S, Gregori A, Fumelli D, Olivieri F, Mazzanti L, Rabini RA: Platelet nitric oxide production and IR: relation with obesity and hypertriglyceridemia. Nutr Metab Cardiovasc Dis 2008, 18:553-558.

40. Ferretti G, Rabini RA, Bacchetti T, Vignini A, Salvolini E, Ravaglia F, Curatola G, Mazzanti L: Glycated low-density lipoproteins modify platelet properties: a compositional and functional study. J Clin Endocrinol Metab 2002, 87:2180-2184

41. Brites FD, Verona J, Schreier LE, Fruchart JC, Castro GR, Wikinski RL: Paraoxonase 1 and platelet-activating factor acetylhydrolase activities in patients with low HDL-cholesterol levels with or without primary hypertriglyceridemia. Arch Med Res 2004, 35:235-240.

42. DiChiara J, Bliden KP, Tantry US, Hamed MS, Antonino MJ, Suarez TA, Bailon $O$, Singla A, Gurbel PA: The effect of aspirin dosing on platelet function in diabetic and nondiabetic patients: an analysis from the Aspirin-Induced Platelet Effect (ASPECT) study. Diabetes 2007, 56:3014-3019.

43. Calkin AC, Drew BG, Ono A, Duffy SJ, Gordon MV, Schoenwaelder SM, Sviridiv D, Cooper ME, Kingwell BA, Jackson SP: Reconstituted high-density lipoprotein attenuates platelet function in individuals with type 2 diabetes mellitus by promoting cholesterol efflux. Circulation 2009, 120:2095-2104.

44. Stalenhoef AFH, de Graaf J: Association of fasting and nonfasting serum triglycerides with cardiovascular disease and the role of remnant-like lipoproteins and small dense LDL. Curr Opin Lipidol 2008, 19:355-361.

45. De Man FH, Nieuwland R, van der Laarse A, Romijn F, Smelt AH, Gevers Leuven JA, Sturk A: Activated platelets in patients with severe hypertriglyceridemia: effects of triglyceride-lowering therapy. Atherosclerosis 2000, 152:407-414

46. Pedreño J, Hurt-Camejo E, Wiklund O, Badimón L, Masana L: Platelet function in patients with familial hypertriglyceridemia: evidence that platelet reactivity is modulated by Apolipoproteine $\mathrm{E}$ content of very low-density lipoprotein particles. Metabolism 2000, 49:942-949.

47. Koga H, Sugiyama S, Kugiyama K, Fukushima H, Watanabe K, Sakamoto T, Yoshimura M, Jinnouchi H, Ogawa H: Elevated levels of remnant lipoproteins are associated with plasma platelet microparticles in patients with type-2 diabetes mellitus without obstructive coronary artery disease. Eur Heart J 2006, 27:817-823.
48. Kolovou GD, Mikhailidis DP, Nordestgaard BG, Bilianou H, Panatopoulos G: Definition of postprandial lipaemia. Curr Vasc Pharmacol 2011, 9:292-301.

49. Nordestgaard BG, Freiberg JJ: Clinical relevance of non-fasting and postprandial hypertriglyceridemia and remnant cholesterol. Curr VasC Pharmacol 2011, 9:281-286.

50. Aznar J, Santos MT, Vallés J: Effect of postprandial lipaemia on platelet function in man evaluated in whole blood. Thromb Res 1987, 48:567-576

51. Brezinski DA, Tofler GH, Müller JE, Pohjola-Sintonen S, Willich SN, Schafer Al Czeisler CA, Williams GH: Morning increase in platelet aggregability. Association with assumption of the upright posture. Circulation 1988, 78:35-40.

52. Jafri SM, VanRollins M, Ozawa T, Mammen EF, Goldberg AD, Goldstein S: Circadian variation in platelet function in healthy volunteers. Am J Cardiol 1992, 69:951-954.

53. May JA, Fox S, Glenn J, Craxford S, Heptinstall S: Platelet function reduces significantly during the morning. Platelets 2008, 19:556-558.

54. Boberg M, Vessby B, Croon LB: Fatty acid composition of platelets and of plasma lipid esters in relation to platelet function in patients with ischaemic heart disease. Atherosclerosis 1985, 58:49-63.

55. García-Guerra R, Mateo CR, García-Munoz MS, Zapata MA, Plaza I, González-Rodríguez J: Distinct cholesterol and phospholipid incorporation at the platelet plasma membrane of hyperlipidemic subjects: structural order and function. Platelets 1998, 9:365-373.

56. Sinzinger $\mathrm{H}$, Flores J, Widhalm $\mathrm{K}$, Granegger S: Platelet viability (aggregation, migration, recovery) after radiolabelling from hypercholesterolemics using various tracers (oxine, oxine-sulphate, tropolone, MPO). Eur J Nucl Med 1988, 14:358-361.

57. Lopez-Miranda J, Delgado-Lista J, Perez-Martinez P, Jimenez-Gómez Y, Fuentes F, Ruano J, Marin C: Olive oil and the haemostatic system. Mol Nutr Food Res 2007, 51:1249-1259.

58. Smith RD, Kelly CN, Fielding BA, Hauton D, Silva KD, Nydahl MC, Miller GJ, Williams CM: Long-term monounsaturated fatty acid diets reduce platelet aggregation in healthy young subjects. Brit J Nutr 2003, 90:597-606.

59. Virgolini I, Koller E, Li S, Yang Q, Banyai M, Rauscha F, Pidlich J, Pirker W, Sinzinger $\mathrm{H}$ : Etofibrate increases binding of low and high density lipoprotein to human platelets of patients with type II hyperlipoproteinemia. Atherosclerosis 1993, 102:217-226.

60. Virgolini I, Li S, Qiong Y, Koller E, Banyai M, Angelberger P, Sinzinger H: Binding of ${ }^{111}$ In-labeled LDL to platelets of normolipemic volunteers and patients with heterozygous familial hypercholesterolemia. Arteriosd Thromb 1993, 13:536-547.

61. Virgolini I, Li S, Yang Q, Banyai M, Koller E, Angelberger $P$, Sinzinger H: Binding of ${ }^{111}$ In-labeled HDL to platelets from normolipemic volunteers and patients with heterozygous familial hypercholesterolemia. Arterioscler Thromb 1992, 12:849-961.

62. Santilli F, Formoso G, Sbraccia P, Averna M, Miccoli R, Di Fulvio P, Ganci A, Pulizzi N, Lattanzio S, Ciabattoni G, Consoli A, Lauro R, Patrono C, Davi G: Postprandial hyperglycemia is a determinant of platelet activation in early type 2 diabetes mellitus. J Thromb Haemost 2010, 8:828-837.

63. Assert R, Scherk G, Bumbure A, Pirags V, Schatz H, Pfeiffer AF: Regulation of protein kinase $C$ by short term hyperglycaemia in human platelets in vivo and in vitro. Diabetologia 2001, 44:188-195.

64. Saleh JW, Hashim SA: Altered sedimentation behaviour and ultrastructure of platelets in hyperlipidemia. Circulation 1974, 50:880

65. Silberbauer KF, Sinzinger H, Haselberger K, Barcsak T, Willvonseder R: Zum physikalischen und funktionellen Verhalten der Thrombozyten bei primären und sekundären Hyperlipoproteinämien. Vasa 1977, 6:148-153.

66. Kolovou GD, Mikhailidis DP, Kovar J, Lairon D, Nordestgaard BG, Ooi TC, Perez-Martinez P, Bilianou H, Anagnostopoulou K, Panotopoulos G: Assessment and clinical relevance of non-fasting and postprandial triglycerides: an expert panel statement. Curr Vasc Pharmacol 2011, 9:258-270.

doi:10.1186/1477-9560-10-19

Cite this article as: Sinzinger and Berent: Platelet function in the postprandial period. Thrombosis Journal 2012 10:19. 